20

\title{
Мониторинг изменения содержания кислорода в тканях по кинетике замедленной флуоресценции экзогенных красителей
}

\author{
(ㄷ С.Н. Летута, С.Н. Пашкевич, Э.К. Алиджанов, Ю.Д. Лантух, Д.А. Раздобреев, А.А. Чакак, А.Т. Ишемгулов \\ Оренбургский государственный университет, \\ 460018 Оренбург, Россия \\ ฯ e-mail: azamat.ischemgulov@yandex.ru
}

Поступила в редакцию 24.12.2018 г.

В окончательной редакции 27.08.2019 г.

Принята к публикации 09.09.2019 г.

\begin{abstract}
Исследована динамика потребления кислорода при фотодинамических процессах и последующее восстановление его содержания в злокачественных опухолях и здоровых тканях мышей in vitro по кинетике длительной люминесценции ксантеновых красителей. Показано, что для оценки изменения концентрации кислорода в тканях можно использовать замедленную флуоресценцию, обусловленную синглет-триплетной аннигиляцией синглетного кислорода и сенсибилизатора в триплетном состоянии. В опухолях при импульсно-периодическом возбуждении сенсибилизаторов обнаружено обратимое тушение замедленной флуоресценции, которое связано с уменьшением количества кислорода в тканях в ходе фотодинамических процессов. Предложен способ наглядной визуализации восстановления исходного содержания кислорода в тканях.
\end{abstract}

Ключевые слова: синглет-триплетная аннигиляция возбужденных состояний, фотодинамическое действие, замедленная флуоресценция.

DOI: $10.21883 /$ OS.2019.12.48706.377-18

\section{Введение}

Информация о содержании кислорода в живых тканях важна для диагностики состояния организма, распознавания патологических процессов и прогноза их развития. Сведения о количестве кислорода в тканях используются для своевременного решения проблем их оксигенации, регулирования эффективности транспорта кислорода при различных заболеваниях, напряженной мышечной работе или снижении парциального давления кислорода в воздухе. От количества кислорода в тканях зависит эффективность неинвазивного метода лечения - фотодинамической терапии (ФДТ, PDT - photodynamic therapy). В клинических условиях сведения об уровне кислорода в тканях желательно получать в режиме реального времени, чтобы в случае необходимости корректировать параметры лечения. Среди известных методов быстрого и удобного мониторинга содержания кислорода в тканях выделяют оптические методы, в том числе основанные на измерении люминесценции молекулярных зондов [1-7].

Динамику изменения концентрации тканевого кислорода при фотодинамических процессах можно исследовать по кинетике замедленной люминесценции эндогенных или экзогенных фотосенсибилизаторов (ФС, $P S)$. В качестве экзогенных ФС часто используют порфирины или другие органические красители [3-5]. Замедленная люминесценция таких зондов возникает в результате излучательной релаксации возбужденных триплетных $T_{1}$-состояний молекул. Интенсивность и длительность свечения зависят от микроокружения ФС.
Наличие в среде тушителей $T_{1}$-состояний молекул ФС существенно влияет на параметры их люминесценции. Эффективным тушителем триплетных состояний ФС является молекулярный кислород ${ }^{3} \mathrm{O}_{2}$. В результате взаимодействия кислорода ${ }^{3} \mathrm{O}_{2}$ с молекулой ФС в триплетном состоянии образуется синглетный кислород ${ }^{1} \mathrm{O}_{2}$ : $T_{1}+{ }^{3} \mathrm{O}_{2} \rightarrow S_{0}+{ }^{1} \mathrm{O}_{2}$ (рис. 1). Синглетный кислород ${ }^{1} \mathrm{O}_{2}$ является непосредственным участником фотодинамических процессов в облучаемых тканях [1-3]. Некоторые методы оценки уровня кислорода в тканях и эффективности генерации ${ }^{1} \mathrm{O}_{2}$ в различных средах обсуждаются в работах [7-29].
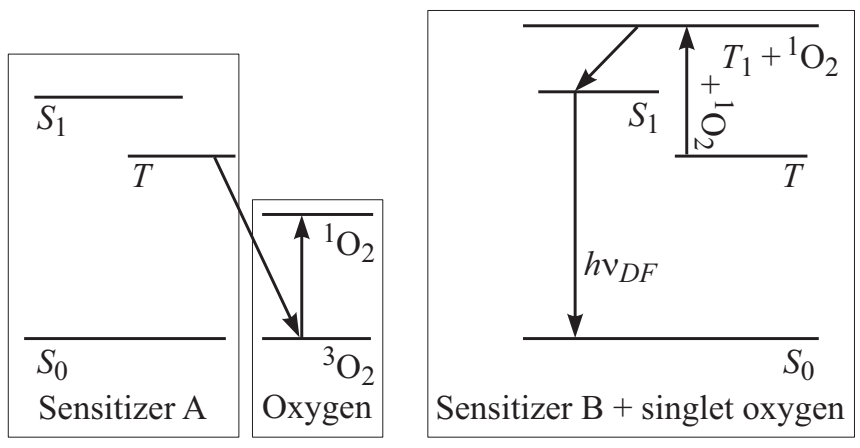

Рис. 1. Схема генерации АЗФ при аннигиляции возбужденных состояний ${ }^{1} \mathrm{O}_{2}$ и $T_{1}$. Синглетный кислород образуется в ходе переноса энергии с сенсибилизатора $A$ на молекулярный кислород (слева). Затем молекула ${ }^{1} \mathrm{O}_{2}$ образует комплекс с другим ФС в $T_{1}$-состоянии, в результате сенсибилизатор $B$ переходит в $S_{1}$-состояние с излучением кванта АЗФ (справа). 
Количественная оценка содержания ${ }^{1} \mathrm{O}_{2}$ в биологических тканях возможна различными люминесцентными способами. Наиболее очевидным является измерение его ИК люминесценции: ${ }^{1} \mathrm{O}_{2} \rightarrow{ }^{3} \mathrm{O}_{2}+h v_{i r}$, однако стабильный сигнал ${ }^{1} \mathrm{O}_{2}$ в биологических системах обнаружить крайне сложно из-за интенсивного тушения ${ }^{1} \mathrm{O}_{2}$ и низкой чувствительности детекторов в данной области спектра [9-13]. Многочисленные косвенные методы основаны на регистрации люминесценции зондов, так или иначе изменяющейся в присутствии кислорода. Например, предлагаются специальные молекулярные зондовые индикаторы [14-18]. Люминесцентные свойства таких индикаторов изменяются в ходе химических реакций с ${ }^{1} \mathrm{O}_{2}$. Излучение зонда значительно удобнее регистрировать, поскольку оно, как правило, происходит в видимом диапазоне спектра. Однако локализация зонда в клетке может не совпасть с локализацией ФС - основного источника ${ }^{1} \mathrm{O}_{2}$. Кроме того, химические реакции зондов c ${ }^{1} \mathrm{O}_{2}$ исключают некоторую часть кислорода и молекул ФС из целевого процесса.

Об относительном изменении количества кислорода в ткани можно судить по тушению кислородом люминесценции ФС, возникающей в результате излучательной релаксации их $T_{1}$-состояний [19-23]. Можно наблюдать как фосфоресценцию: $T_{1} \rightarrow S_{0}+h v_{P}$, так и замедленную флуоресценцию (ЗФ, DF - delayed fluorescence), обусловленную обратной интеркомбинационной конверсией: $T_{1} \rightarrow S_{1} \rightarrow S_{0}+h v_{d f}$. Такая ЗФ известна как ЗФ „типа $E^{\text {“ }}$ или „термоактивационная замедленная флуоресценция“ (ТЗФ) [24]. С ростом концентрации кислорода в среде квантовый выход фосфоресценции и ТЗФ уменьшается. Однако некоторые молекулы ФС могут быть недоступны для тушения, и их люминесценция может давать посторонний вклад в регистрируемый сигнал.

Если молекулы кислорода в среде подвижны, при определенных условиях реализуется другой механизм генерации ЗФ. В ходе взаимодействия ${ }^{1} \mathrm{O}_{2}$ с $T_{1}$-молекулой ФС существует конечная вероятность образования $S_{1}$-состояния ФС в реакции: $T_{1}+{ }^{1} \mathrm{O}_{2} \rightarrow S_{1}+{ }^{3} \mathrm{O}_{2}$, а излучательная релаксация $S_{1}$-состояния ФС дает дополнительный вклад в ЗФ $[25,26]$ (рис. 1). Длительную люминесценцию, возникающую в результате аннигиляции возбужденных состояний $\left(T_{1}+{ }^{1} \mathrm{O}_{2}\right)$ будем называть далее „аннигиляционной“ (АЗФ).

Стоит отметить, что возможен другой „аннигиляционный“ механизм возникновения ЗФ, обусловленный взаимной аннигиляцией двух триплетных возбуждений $\Phi С: T_{1}+T_{1} \rightarrow S_{0}+S_{1} \rightarrow S_{0}+S_{0}+h v_{d f}$. Однако в биологических системах подвижность молекул красителей ограничена $[21,22]$, и вкладом процесса $T_{1}+T_{1}$ в наблюдаемую ЗФ можно пренебречь.

Особенности АЗФ различных ФС достаточно подробно изучены для небиологических систем [25-29], однако в живых клетках и тканях такой тип длительной люминесценции исследован очень фрагментарно [3032]. Использование АЗФ имеет ряд преимуществ. АЗФ наблюдается в видимой части спектра и непосредственно зависит от фотодинамической активности ${ }^{1} \mathrm{O}_{2}$, тогда как другие типы длительной люминесценции - фосфоресценция и ТЗФ позволяют оценить лишь тушение кислородом ${ }^{3} \mathrm{O}_{2}$ триплетных состояний ФС. Если константа скорости процесса $\left(T_{1}+{ }^{1} \mathrm{O}_{2}\right)$ достаточно велика, то посредством АЗФ возможен мониторинг изменения концентрации кислорода в тканях. В настоящей работе продемонстрированы возможности использования АЗФ экзогенных красителей для мониторинга фотодинамического потребления ${ }^{1} \mathrm{O}_{2}$ в живых тканях и применение такого свечения для визуализации восстановления оксигенации тканей после фотодинамического воздействия.

\section{Материалы и методы}

Объектами исследования служили интактные ткани мышей линии BYRB-Rb (8/17)1Lem (Институт биоорганической химии РАН им. М.М. Шемякина и Ю.А. Овчинникова). У самок мышей этой линии на определенном этапе их жизни спонтанно формируются злокачественные опухоли молочных желез [33]. В настоящей работе представлены результаты исследования тканей 50 больных и 15 здоровых мышей. Фрагменты тканей были отобраны хирургическим путем. Время между началом операции и завершением всех экспериментов не превышало $1 \mathrm{~h}$.

В качестве ФС использовались ксантеновые красители: эритрозин В, эозин Y, эозин В и бенгальский розовый. Красители данного типа используются в гистологии для визуализации компонентов цитоплазмы клеток и связываются преимущественно с белками [3,34]. Они имеют высокий квантовый выход в триплетное состояние в водных растворах, интенсивную ЗФ с максимумом в полосе 560-570 nm и фосфоресценцию с максимумом в полосе 670-690 nm. Спектры поглощения красителей в водных растворах представлены на рис. 2.

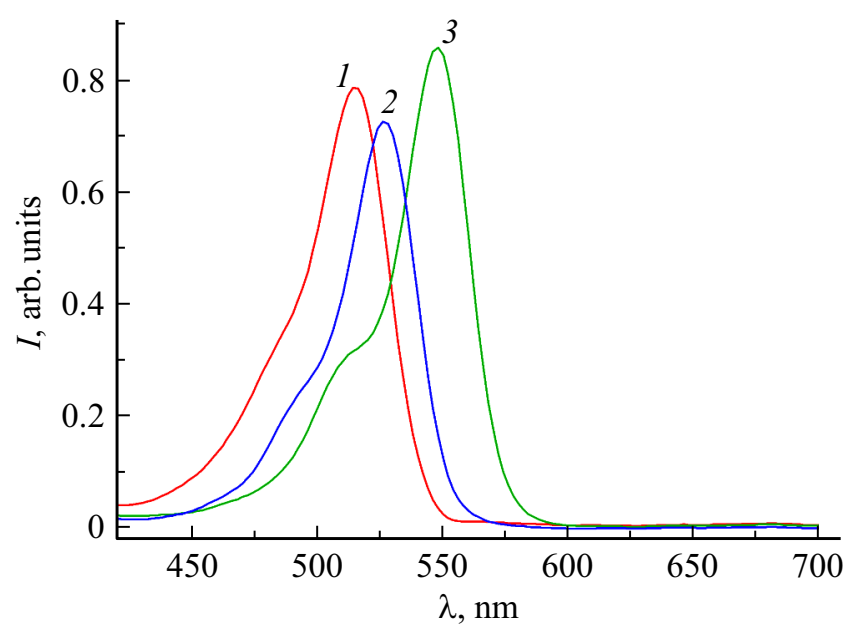

Рис. 2. Спектры поглощения водных растворов эозина (1), эритрозина (2), бенгальского розового (3) с концентрацией $10^{-5} \mathrm{M}$ 
Окрашивание образцов проводили путем погружения фрагментов ткани в водный раствор красителя с концентрацией $1 \mathrm{mM}$ на 2 min с последующей промывкой в $0.9 \%$ физрастворе. Затем образцы окрашенных тканей помещали в термостатируемую камеру, что позволяло сохранять физиологическую температуру $37^{\circ} \mathrm{C}$. Для регулирования количества кислорода в тканях к камере подключался баллон с газообразным азотом. При продувании камеры азотом можно добиться снижения содержания кислорода в образцах без их повреждения.

Для экспериментов in vivo животное обездвиживалось, далее под наркозом обнажался фрагмент ткани на уровне молочной железы. Затем открытая ткань промывалась и окрашивалась несколькими каплями раствора эритрозина $1 \mathrm{mM}$, после чего закрывалась покровным стеклом для исключения доступа атмосферного воздуха.

Кинетика длительной люминесценции ФС исследована методом флеш-фотолиза. В качестве импульсного источника света использовалась вторая гармоника $\mathrm{YAG}: \mathrm{Nd}^{3+}$-лазера. Параметры возбуждения: длина волны $532 \mathrm{~nm}$, длительность импульса $\sim 15 \mathrm{ns,} \mathrm{плотность}$ мощности возбуждения $\sim 0.5 \mathrm{MW} \cdot \mathrm{cm}^{-2}$, доза облучения $1-2 \mathrm{~mJ} \cdot \mathrm{cm}^{-2}$ за один импульс. Возбуждение производилось как одиночными импульсами, так и сериями до 10 лазерных импульсов с частотой в диапазоне 0.1-10 Hz. Длительная люминесценция регистрировалась через монохроматор МДР-41 с помощью ФЭУ-84 с управляющим электродом, который позволял регулировать чувствительность приемника. При записи спектров длительной люминесценции ФС в тканях интенсивность каждой точки определялась по площади под соответствующей кинетической кривой.

\section{Результаты и обсуждение}

На рис. 3, а показаны кинетические кривые ЗФ эритрозина в злокачественной опухоли молочной железы мыши в обычной атмосфере (на воздухе) и в атмосфере азота. Видно, что при длительном выдерживании образцов в атмосфере азота (кривая 2 на рис. 3,a) на начальном участке кривой затухания ЗФ в интервале времени $0-10 \mu$ s интенсивность свечения отчетливо снижается. При этом форма кинетической кривой ЗФ приближается к моноэкспоненциальной. При обратной подаче воздуха в камеру с образцами форма кривой и интенсивность ЗФ красителя восстанавливаются, т.е. изменения кинетической кривой затухания ЗФ обратимы.

Практически весь наблюдаемый сигнал ЗФ красителей в живых тканях формируется только из двух компонент: ТЗФ и АЗФ [31,32]. Генерация АЗФ диффузионно-контролируемый процесс, сильно зависящий от плотности $T_{1}$-состояний ФС и времени жизни ${ }^{1} \mathrm{O}_{2}$. После окончания импульсного возбуждения (при наличии подвижных молекул кислорода в среде) количество $T_{1}$-состояний быстро уменьшается, поскольку одновременно идут реакции их тушения молеку-
Относительные интегральные интенсивности ЗФ $I_{n} / I_{1}$ и продолжительность ЗФ $\tau$ эритрозина в опухоли молочной железы мыши при импульсно-периодическом возбуждении

\begin{tabular}{c|c|c|c|c}
\hline \multirow{2}{*}{$\begin{array}{c}\text { № } \\
\text { импульса } \\
\text { возбуж- } \\
\text { дения }\end{array}$} & \multicolumn{2}{|c|}{ Частота следования возбуждающих импульсов } \\
\cline { 2 - 5 } & $I_{n} / I_{1}$ & $t, \mu \mathrm{s}$ & $I_{n} / I_{1}$ & $t, \mu \mathrm{s}$ \\
\hline 1 & $1.00 \pm 0.03$ & $2.54 \pm 0.08$ & $1.00 \pm 0.04$ & $2.50 \pm 0.06$ \\
2 & $0.85 \pm 0.02$ & $2.62 \pm 0.06$ & $0.72 \pm 0.04$ & $2.98 \pm 0.08$ \\
3 & $0.78 \pm 0.03$ & $2.76 \pm 0.07$ & $0.68 \pm 0.03$ & $3.11 \pm 0.07$ \\
7 & $0.70 \pm 0.03$ & $2.99 \pm 0.08$ & $0.61 \pm 0.04$ & $3.17 \pm 0.09$ \\
10 & $0.67 \pm 0.04$ & $3.10 \pm 0.10$ & $0.60 \pm 0.04$ & $3.20 \pm 0.08$
\end{tabular}

лярным кислородом, а также реакции генерации АЗФ $\left(T_{1}+{ }^{1} \mathrm{O}_{2}\right)$. Из экспериментальных кривых видно, что АЗФ доминирует в диапазоне $0-10 \mu \mathrm{s}$. На более поздних временах скорость затухания ЗФ сильно замедляется и приближается к моноэкспоненциальной (рис. 3,a), т.е. представлена главным образом ТЗФ, образующейся в результате собственного распада $T_{1}$-состояний. На этой стадии процесса плотность $T_{1}$-состояний ФС уже снижается настолько, что вероятность вновь образованной молекулы ${ }^{1} \mathrm{O}_{2}$ найти пару для $\left(T_{1}+{ }^{1} \mathrm{O}_{2}\right)$ аннигиляции очень мала.

При облучении тканей экспериментальных животных в импульсно-периодическом режиме с фиксированной частотой выше $1 \mathrm{~Hz}$ в некоторых образцах происходит уменьшение интенсивности ЗФ. Наблюдаемый эффект будем называть „световым тушением замедленной флуоресценции“ (СТЗФ) [31]. Для иллюстрации эффекта СТЗФ на рис. $3, b$ показаны кинетические кривые затухания ЗФ эритрозина в опухоли молочной железы мыши при частоте возбуждения $5 \mathrm{~Hz}$ после первого и седьмого импульсов возбуждения. СТЗФ тем более выражено, чем меньше время между возбуждающими импульсами и больше энергия возбуждения. Если временной интервал между возбуждающими импульсами превышает 3-5 s, эффект СТЗФ не наблюдается, а кинетические кривые затухания ЗФ не изменяются от импульса к импульсу. Тушение интегральной интенсивности ЗФ в интервале времени $1-5 \mu \mathrm{s}$ при разных частотах следования возбуждающих импульсов показано во врезке рис. $3, b$. Аналогичные результаты получены для всех исследованных красителей.

Одновременно с тушением ЗФ увеличивается длительность свечения. В таблице представлены относительные интегральные интенсивности ЗФ в интервале времени $1-5 \mu \mathrm{s}$ и длительность ЗФ эритрозина в опухоли молочной железы мыши при импульсно-периодическом возбуждении с частотами 5 и $10 \mathrm{~Hz}$.

Отметим, что начальные участки кривых на рис. 3 не аппроксимируются одной или двумя экспонентами. Это свидетельствует об одновременном вкладе в 

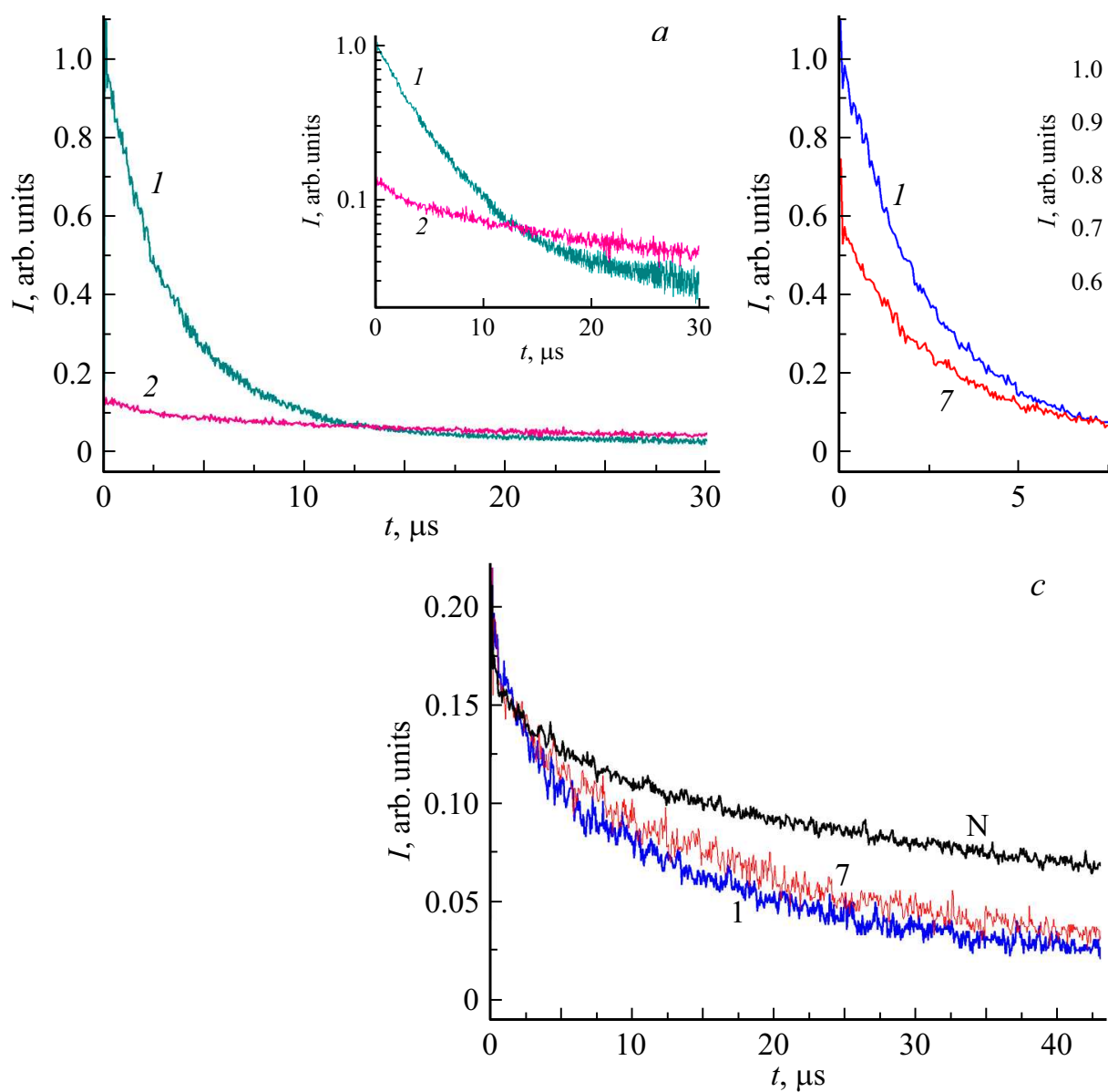

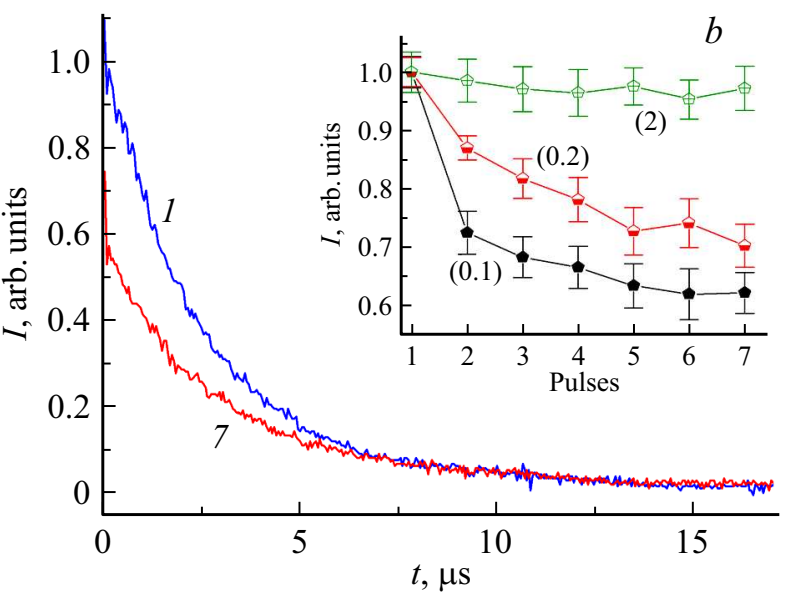

Рис. 3. Кинетика затухания длительной люминесценции эритрозина в злокачественной опухоли молочной железы мыши: $(a)$ 3Ф $(\lambda=560 \mathrm{~nm})$ при нормальных условиях $(1)$ и в атмосфере азота (2). Во врезке те же кривые в полулогарифмических координатах; (b) $3 \Phi(\lambda=560 \mathrm{~nm})$ при импульсно-периодическом возбуждении с частотой $5 \mathrm{~Hz}$ при нормальных условиях (показаны кривые после 1-го и 7-го импульсов). Во врезке - изменение интегральной интенсивности ЗФ в интервале времени $(1-10) \mu$ s при стробвозбуждении с периодом $0.1 ; 0.2$ и $2 \mathrm{~s}$, соответственно; $(c)$ фосфоресценция $(\lambda=680 \mathrm{~nm})$ при тех же условиях, что и для рис. $2, b$ (показаны кривые после 1-го и 7-го импульсов) и в атмосфере азота (кривая N).

наблюдаемую ЗФ различных процессов, которые протекают с разной скоростью. Поэтому термин „время жизни“ в строгом смысле (время, в течение которого начальная интенсивность уменьшается в $e$ раз) некорректен, и использован термин „продолжительность“ свечения.

По мере тушения АЗФ одновременно наблюдается незначительное увеличение интенсивностей ТЗФ и фосфоресценции. Кинетика фосфоресценции после 1-го и 7-го импульсов возбуждения ФС представлена на рис. 3,c. При этом начальная интенсивность фосфоресценции (которая пропорциональна концентрации $T_{1}$ состояний после окончания лазерного возбуждения) остается неизменной. На рис. 4 показано изменение спектров длительной люминесценции эозина в опухоли молочной железы мыши после первого и седьмого импульсов возбуждения в серии. Относительное изменение интегральной интенсивности ЗФ (полоса $550-600 \mathrm{~nm}$ ) намного больше, чем изменение фосфоресценции (полоca $650-720 \mathrm{~nm}$ ).
СТЗФ не связано с обратимыми фотохимическими реакциями или необратимым фотообесцвечиванием ФС. Об этом свидетельствуют по крайней мере три факта. Во-первых, параметры кинетических кривых ЗФ не меняются при низких частотах (ниже $1 \mathrm{~Hz}$ ) стробвозбуждения. При фотообесцвечивании красителя СТЗФ регистрировалось бы при любой частоте. Во-вторых, в окрашенных тканях в широком диапазоне не обнаружено новых полос в спектрах возбуждения флуоресценции красителей или свечения каких-либо возможных продуктов фотореакций. В-третьих, начальная интенсивность фосфоресценции после каждого возбуждающего импульса не изменяется, что указывает на постоянство исходной концентрации ФС. В атмосфере азота эффект СТЗФ не наблюдается.

На основании представленных экспериментальных данных можно утверждать, что причина СТЗФ заключается в кратковременном снижении количества кислорода в облучаемых биотканях. Как видно на рис. $3, a$, удаление кислорода из тканей приводит к значительно- 


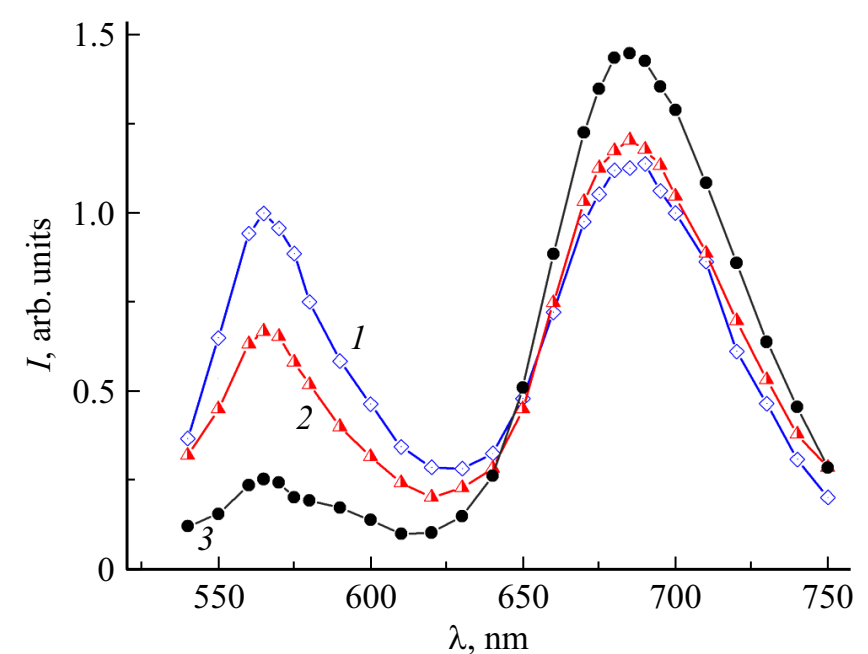

Рис. 4. Спектры длительной люминесценции эозина в опухоли молочной железы мыши после 1-го (1) и 7-го (2) импульсов возбуждения, следовавших с фиксированной частотой $5 \mathrm{~Hz}$ в обычной атмосфере; тот же образец в атмосфере азота (3).

му (и обратимому) уменьшению интенсивности ЗФ в диапазоне времени $0-10 \mu \mathrm{s}$. На этом участке кинетической кривой основной вклад в свечение дает процесс $\left(T_{1}+{ }^{1} \mathrm{O}_{2}\right)$. Лазерное облучение молекул ФС в тканях инициирует генерацию активных форм кислорода, в том числе синглетного кислорода ${ }^{1} \mathrm{O}_{2}$, который является сильным окислителем биотканей [1-3]. Известными мишенями для ${ }^{1} \mathrm{O}_{2}$ в тканях являются белки, ненасыщенные липиды и другие молекулы [1-3,35-39]. Однако чем больше молекул ${ }^{1} \mathrm{O}_{2}$ будет связываться с компонентами тканей (химическое тушение ${ }^{1} \mathrm{O}_{2}$ ), тем меньше в среде будет оставаться свободных молекул кислорода.

Химическое тушение ${ }^{1} \mathrm{O}_{2}$ конкурирует с реакцией $\left(T_{1}+{ }^{1} \mathrm{O}_{2}\right)$, так как оба этих процесса связаны с миграцией в биоткани молекул ${ }^{1} \mathrm{O}_{2}$ в течение его времени жизни (от нескольких десятков до нескольких сотен наносекунд $[4,10,11])$. Однако после реакции $\left(T_{1}+{ }^{1} \mathrm{O}_{2}\right)$ количество кислорода в ткани не изменяется в отличие от химического тушения ${ }^{1} \mathrm{O}_{2}$. Другие каналы релаксации ${ }^{1} \mathrm{O}_{2}$ (внутренняя безызлучательная конверсия или ИК фосфоресценция) также не уменьшают содержания кислорода в тканях.

При снижении концентрации кислорода в ткани увеличивается скорость диффузии свободных молекул кислорода из атмосферы в область облучения. Для образцов in vitro в отличие от условий in vivo атмосфера является единственным резервуаром кислорода. Когда образцы находятся на открытом воздухе, молекулы кислорода проникают в ткани и поддерживают в них определенную концентрацию кислорода. СТЗФ наблюдается тогда, когда скорость дезоксигенации ткани превышает скорость оксигенации.

Таким образом, СТЗФ основано на химическом связывании ${ }^{1} \mathrm{O}_{2}$ с тканевыми компонентами. После каж- дого импульса возбуждения часть ${ }^{1} \mathrm{O}_{2}$ потребляется в ткани. За время между последовательными импульсами возбуждения потери кислорода в ткани частично компенсируются за счет диффузии из атмосферы. Но если время между возбуждающими импульсами мало, то процесс диффузии не может обеспечить полное восстановление исходной концентрации кислорода. Для наблюдения СТЗФ одновременно необходимо соблюдение следующих условий:

- наличие достаточного количества кислорода и ФС;

- высокая восприимчивость тканей к окислению;

- скорость потребления кислорода в ткани больше, чем скорость оксигенации.

По-видимому, не во всех тканях одновременно выполняются эти условия, поэтому СТЗФ регистрировалось только в определенных исследованных образцах. При частоте возбуждения выше $1 \mathrm{~Hz}$ СТЗФ наблюдалось у 90\% образцов злокачественных опухолей мышей и только у $10 \%$ образцов тканей здоровых животных. Установлено, что наиболее отчетливо СТЗФ фиксируется в рыхлых опухолях. Вероятно, такие опухоли содержат много воды и могут накапливать больше водорастворимого ФС. Кроме того, СТЗФ регистрировалось и в других органах мышей (почки и печень) с обнаруженными визуально и подтвержденными гистологически патологиями, но у нас пока недостаточно статистики, чтобы представить надежные количественные данные. Возможно, различный характер СТЗФ в опухолях и здоровых тканях обусловлен тем, что в целом в опухолях накапливается больше $\Phi С$, чем в нормальных тканях, что обеспечивает более интенсивные фотодинамические реакции генерации и потребления ${ }^{1} \mathrm{O}_{2}$ [36-38]. Вероятно, интенсивно делящиеся раковые клетки содержат больше потенциальных мишеней для ${ }^{1} \mathrm{O}_{2}$. Так, например, устойчивость поврежденных белков, которые могут находиться в опухолях, к окислительному действию ${ }^{1} \mathrm{O}_{2}$ снижена [35].

Так как интегральная интенсивность ЗФ на начальном участке с хорошей точностью пропорциональна количеству образуемого ${ }^{1} \mathrm{O}_{2}$ в ткани, а СТЗФ является обратимым, можно отследить не только уменьшение генерации ${ }^{1} \mathrm{O}_{2}$, но и процесс восстановления исходного содержания кислорода до облучения. На рис. 5, $a$ показан способ определения времени восстановления интенсивности и продолжительности ЗФ после СТЗФ с помощью одиночного тестового импульса.

Тестовый импульс (test pulse) подается с регулируемой задержкой (delay) относительно времени последнего импульса в основной серии возбуждения (excitation). Определяя интегральную интенсивность ЗФ после тестовых импульсов с различной временной задержкой, можно видеть, что с увеличением задержки тестового импульса интенсивность ЗФ (т.е. количество образуемого ${ }^{1} \mathrm{O}_{2}$ ) возвращается к изначальной. В качестве иллюстрации на рис. 5, $а$ показаны кинетические кривые затухания ЗФ эритрозина в опухоли молочной железы мыши после 1-го импульса, после 7-го импульса в серии из 7 импульсов, следующих с частотой $10 \mathrm{~Hz}$, 

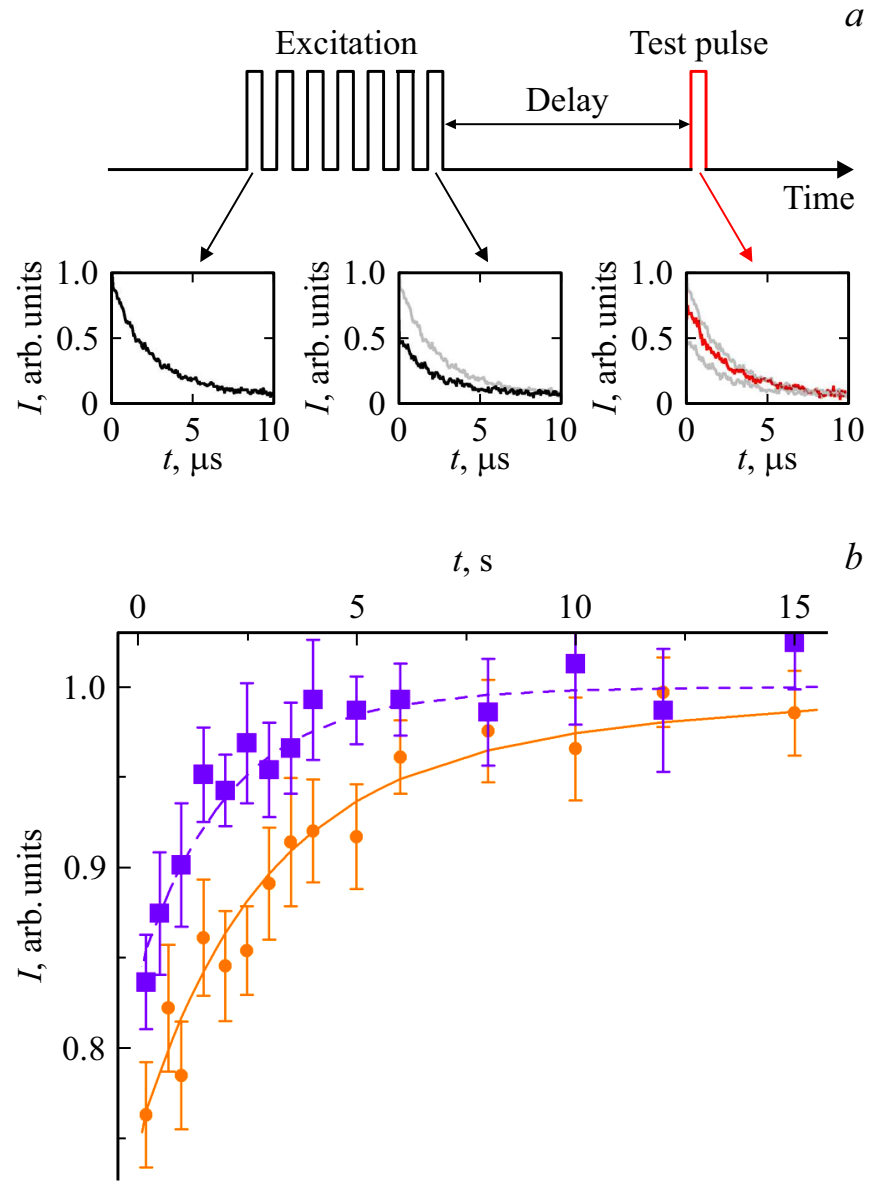

Рис. 5. (а) Схема эксперимента по определению времени восстановления интенсивности ЗФ после СТЗФ с помощью дополнительного (тестового) импульса. (b) Кривая восстановления интенсивности ЗФ эритрозина в опухоли молочной железы мыши после СТЗФ для образцов in vivo (квадраты, штриховая линия) и in vitro (круги, сплошная линия).

и кривая ЗФ после тестового импульса. На рис. 5, $b$ представлена кривая восстановления интенсивности ЗФ эритрозина в опухоли молочной железы мыши после СТЗФ. Каждая точка на графике соответствует площади под кинетической кривой при различной задержке тестового импульса.

Аппроксимирующие кривые для точек на рис. 5, $b$ соответствуют простейшей модели восстановления интенсивности АЗФ, когда скорость восстановления пропорциональна отклонению от равновесного значения

$$
I=I_{0}\left(1-A \exp \left\{-\frac{T}{\theta}\right\}\right)
$$

где $A \approx 0.2, \theta \approx 4.5 \mathrm{~s}$ для случая in vitro и $2.5 \mathrm{~s}$ для случая in vivo. Восстановление содержания кислорода в тканях in vivo происходит быстрее, вероятно, в условиях естественной оксигенации тканей через систему кровообращения.

Отметим, что возбуждение красителей в тканях может быть различным, в том числе и непрерывным. Ключевым в данном подходе является необходимость с помощью одиночного импульса сначала зафиксировать исходную интенсивность ЗФ, а затем с помощью аналогичных импульсов отслеживать поведение интенсивности ЗФ во времени. Такая методика может найти практическое применение. Так, в ходе сеанса ФДТ один и тот же ФС можно использовать как фотодинамический агент и как маркер эффективности производимого действия. Это позволит сравнивать относительное содержание кислорода (или восприимчивость тканей к окислению) в разных областях и определять возможные зоны патологии.

\section{Заключение}

Тушение АЗФ при лазерном импульсно-периодическом возбуждении ФС в тканях наглядно показывает, что содержание кислорода в тканях может существенно снижаться, если скорость оксигенации невысока. Это следует учитывать в сеансах ФДТ, либо обеспечивая облучаемые ткани кислородом дополнительно, либо используя импульсные источники возбуждения вместо непрерывных [38,39].

Изменение содержания кислорода в тканях удобно регистрировать по кинетике АЗФ. Преимущества АЗФ перед другими типами длительной люминесценции состоят в высокой чувствительности к содержанию кислорода и относительно несложной системе регистрации сигналов. В этом случае требуются ФС, отличающиеся фотостабильностью и высоким квантовым выходом АЗФ.

\section{Благодарности}

Работа выполнена при поддержке Министерства образования и науки РФ (проект 3.6358.2017/8.9).

\section{Соблюдение этических стандартов}

Все применимые международные, национальные принципы ухода и использования животных были соблюдены.

\section{Конфликт интересов}

Авторы заявляют, что у них нет конфликта интересов.

\section{Список литературы}

[1] Krasnovsky A.A., Jr. // J. Photochem. Photobiol. 2008. V. 196. P. 210-218. doi 10.1016/j.jphotochem.2007.12.015

[2] Liu W., Zhang X.H., Liu K.P., Zhang S.D., Duan Y.X. // Chinese Science Bulletin. 2013. V. 58. P. 2003-2016. doi 10.1007/s11434-013-5826-y

[3] Ormond A.B., Freeman H.S. // Materials. 2013. V. 6. P. 817-840. doi 10.3390/ma6030817

[4] Berezin M.Y., Achilefu S. // Chem. Rev. 2010. V. 110. P. 2641-2684. doi 10.1021/cr900343z 
[5] Quaranta M., Borisov S.M., Klimant I. // Bioanal. Rev. 2012. V. 4 (2-4). P. 115-157. doi 10.1007/s12566-012-0032-y

[6] Dmitriev R.I., Papkovsky D.B. // Cell. Mol. Life Sci. 2012. V. 69. P. 2025-2039. doi 10.1007/s00018-011-0914-0

[7] Roussakis E., Li Z., Nichols A.J., Evans C.L. // Angew. Chem. Int. Edit. 2015. V. 54 (29). P. 8340-8362. doi 10.1002/anie.201506847

[8] Zach P.W., Freunberger S.A., Klimant I., Borisov S.M. // ACS Appl. Mater. Interfaces. 2017. V. 9 (43). P. 38008-38023. doi $10.1021 /$ acsami.7b10669

[9] Niedre M., Patterson M.S., Wilson B.C. // Photochem. Photobiol. 2002. V. 75. P. 382-391. doi 10.1562/00318655(2002)0750382DNILDO2.0.CO2

[10] Mik E.G. // Anesth Analg. 2013. V. 117. P. 834-846. doi 10.1213/ANE.0b013e31828f29da

[11] Snyder J.W., Zebger I., Gao Z., Poulsen L., Frederiksen P.K., Skovsen E., Mcllroy S.P., Klinger M., Andersen L.K., Ogilby P.R. // Acc. Chem. Res. 2004. V. 37. P. 894-901. doi 10.1021/ar040075y

[12] Li B., Lin H., Chen D., Wilson B.C., Gu Y.J. // Innov. Opt. Health Sci. 2013. V. 6. P. 1330002. doi $10.1142 / \mathrm{S} 1793545813300024$

[13] Koh E., Fluhr R. // Plant Signal Behav. 2016. V. 11. P. e1192742. doi 10.1080/15592324.2016.1192742

[14] Kessel D., Price M. // Photochem. Photobiol. 2012. V. 88. P. 717-720. doi 10.1111/j.1751-1097.2012.01106.x

[15] Flors C., Fryer M.J., Waring J., Reeder B., Bechtold U., Mullineaux P.M., Nonell S., Wilson M.T., Baker N.R. // J. Exp. Bot. 2006. V. 57. P. 1725-1734. doi 10.1093/jxb/erj181

[16] Gollmer A., Arnbjerg J., Blaikie F.H., Pedersen B.W., Breitenbach T., Daasbjerg K., Glasius M., Ogilby P.R. // Photochem. Photobiol. 2011. V. 87. P. 671-679. doi 10.1111/j.1751-1097.2011.00900.x

[17] Luengas S.L.P., Marín G.H., Aviles K., Acuña R.C., Roque G., Nieto F.J.R., Sánchez F., Tarditi A., Rivera L., Mansilla E.V. // Cancer Biother. Radiopharm. 2014. V. 29. P. 435-443. doi 10.1089/cbr.2014.1718

[18] You M.X., Wang Y.X., Wang H., Yang R.H. // Chinese Sci. Bull. 2011. V. 56. P. 3253-3259.

[19] Kurokawa H., Ito H., Inoue M., Tabata K., Sato Y., Yamagata K., Kizaka-Kondoh Sh., Kadonosono T., Yano Sh., Inoue M., Kamachi T. // Sci. Rep. 2015. V. 5. P. 10657. doi 10.1038/srep10657

[20] Mik E.G., Stap J., Sinaasappel M., Beek J.F., Aten J.A., van Leeuwen T.G., Ince C. // Nat. Methods 2006. V. 3 (11). P. 939-945. doi 10.1038/nmeth940

[21] Losev A.P., Knyukshto V.N., Zhuravkin I.N. // J. Appl. Spectr. 1991. V. 60. P. 71-76. doi 10.1007/BF02606080

[22] Feng T., Grusenmayer T.A., Lupin M., Schmehl R.H. // Photochem. Photobiol. 2015. V. 91. P. 705-713. doi $10.1111 /$ php. 12381

[23] Nugent W.H., Song B.K., Pittman R.N., Golub A.S. // Microvasc. Res. 2016. V. 105. P. 15-22. doi 10.1016/j.mvr.2015.12.007

[24] Parker C.A., Hatchard C.G. // Trans. Faraday Soc. 1961. V. 57. P. 1894-1904.

[25] Kautsky H., Müller G.O. // Z. Naturforschung A. 1947. V. 2. P. $167-172$.

[26] Bolton P.H., Kenner R.D., Khan A.U. // J. Chem. Phys. 1972. V. 57. P. 5604.

[27] Kucherenko M.G., Melnik M.P. // J. Eur. Opt. Soc. 1994. V. 3. P. 235-241.
[28] Bryukhanov V.V., Ketsle G.A., Laurinas V.Ch., Levshin L.V., Muldakhmetov Z.M. // J. Appl. Spectr. 1987. V. 46. P. 372-377. doi 10.1007/BF00660047

[29] Vinklárek I.S., Scholz M., Dědic R., Hála J. // Photochem. Photobiol. Sci. 2016. V. 16. P. 507-518. doi 10.1039/c6pp00298f

[30] Scholz M., Biehl A., Dědic R., Hála J. // Photochem. Photobiol. Sci. 2013. V. 12. P. 1873-1884. doi 10.1039/C6PP00298F

[31] Letuta S.N., Pashkevich S.N., Ishemgulov A.T., Lantukh Yu.D., Alidzhanov E.K., Sokabaeva S.S., Bryukhanov V.V. // J. Photochem. Photobiol. B. 2016. V. 163. P. 232-236. doi 10.1016/j.jphotobiol.2016.08.036

[32] Ишемгулов А.Т., Летута С.Н., Пашкевич С.Н., Алиджанов Э.К., Лантух Ю.Д. // Опт. и спектр. 2017. Т. 123. C. 818-824; Ishemgulov A.T., Letuta S.N., Pashkevich S.N., Alidzhanov E.K., Lantukh Yu.D. // Opt. and Spectr. 2017. V. 123. P. 828-834. doi 10.7868/S0030403417110095

[33] Moiseeva E.V. Original approaches to test anti-breast cancer drugs in a novel set of mouse models // Proefschrift Universiteit Utrecht, 2005. - $191 \mathrm{p}$.

[34] Garg A.D., Bose M., Ahmed M.I., Bonass W.A., Wood S.R. // PLoS One. 2012. V. 7. P. e34475. doi 10.1371/journal.pone.0034475

[35] Jensen R.L., Arnbjerg J., Birkedal H., Ogilby P.R. // J. Am. Chem. Soc. 2011. V. 133. P. 7166-7173. doi $10.1021 / j a 2010708$

[36] Carreau A., El Hafny-Rahbi B., Matejuk A., Grillon C., Kieda C. // J. Cell. Mol. Med. 15, 1239-1253 (2011). doi 10.1111/j.1582-4934.2011.01258.x

[37] Alberts B., Johnson A., Lewis J., Raff M., Roberts K., Walter P. Molecular Biology of the Cell, 4th ed, Garland Science, New York, 2002.

[38] Pandey R.K., Kessel D., Dougherty T.J. Handbook of photodynamic therapy. Updates on recent applications of porphyrin-based compounds, World Scientific Pub Co Inc., 2016.

[39] Chen Q., Huang Z., Chen H., Shapiro H., Beckers J., Hetzel F.W. // Photochem. Photobiol. 2002. V. 76. P. 197-203. doi 10.1562/0031-8655(2002)0760197IOTRBM2.0.CO2 